\title{
HUBUNGAN PENGETAHUAN DAN SIKAP TERHADAP TINDAKAN CUCI TANGAN PAKAI SABUN (CTPS)
}

\author{
Ernawati $^{1}$, Eka Rora Suci Wisudawati ${ }^{2}$, M. Romadhon ${ }^{3}$ \\ Program Studi S-I Ilmu Keperawatan, dan D-III Keperawatan Fakultas Kebidanan dan Keperawatan \\ Universitas Kader Bangsa Palembang \\ Jl. Mayjend H.M. Ryacudu No. 88 Pangkal Ampera 7 Ulu Palembang \\ Email : ernawati10489@gmail.com
}

\begin{abstract}
Abstrak
Perilaku hidup bersih dan sehat yang sederhana seperti mencuci tangan dengansabun merupakan salah satu cara untuk meningkatkan kesadaran masyarakat tentang pemeliharaan kesehatan pribadi dan pentingnya berperilaku hidup bersih dan sehat (Retno,2016). Kesadaran masyarakat Indonesia untuk cuci tangan pakai sabun (CTPS) terbukti masih sangat rendah, Green dalam Notoatmojo (2017) menyebutkan bahwa Perilaku kesehatan dapat dipengaruhi oleh tiga faktor diantaranya yaitu Faktor predisposisi pada seesorang diantaranya pengetahuan, sikap, keyakinan, nilai-nilai, persepsi, usia, status sosial ekonomi, jenis kelamin yang menjadi pemicu seseorang melakukan tindakan. Desain penelitian yang digunakan oleh peneliti adalah metode cross sectional, Sampel diambil secara random sampling yang berjumlah 67 responden. Hasil penelitian mengatakan bahwa ada hubungan antara pengetahuan p-value 0,002, sikap nilai p-value 0,009 dengan tindakan CTPS. Hasil penelitian ini diharpakan dapat bahan evaluasi untuk mengembangkan kesehatan khususnya tentang pendidikan Cuci Tangan Pakai Sabun (CTPS).
\end{abstract}

\section{Kata kunci-Perilaku, Cuci Tangan Pakai Sabun}

\begin{abstract}
Healthy and Clean Life Behavior in a simple way such as wash hands with soap is one of the way to increase the people awareness about personal hygiene and the importance of healthy and clean life behavior principle (Retno, 2016). In fact, the awareness of Indonesian people to get used to cleaning hands with soap is still poor. According to Green, in Notoatmojo (2017) states that healthy behavior can be influenced by three factors, one of them is predisposition to someone such as knowledge, behavior, faith, value, perception, age, status of economy and social level, gender that could be a trigger of someone to behave. The research design done by the researcher is Cross Sectional method, and the samples done by using random sampling for 67 respondents. The result of the research show that there is a correlation between knowledge with p-value $=0.002$, behavior with p-value $=0.009$, to CTPS. The result of the research is expected to become an evaluation to develop health program especially about washing hands with soap (CTPS).
\end{abstract}

Keywords $\quad$ : Behavior, Washing hands with soap 


\section{PENDAHULUAN}

Perilaku hidup bersih dan sehat yang sederhana seperti mencuci tangan dengansabun merupakan salah satu cara untuk meningkatkan kesadaran masyarakat tentang pemeliharaan kesehatan pribadi dan pentingnya berperilaku hidup bersih dan sehat (Retno, 2016). Perilaku Cuci Tangan Pakai Sabun (CTPS) merupakan salah satu aspek yang menjadi indikator dalam PHBS yang saat ini menjadi perhatian dunia. Hal ini disebabkan tidak hanya di Negara berkembang, namun juga di Negara maju, masih banyak masyarakat yang lupa melakukan Cuci Tangan Pakai Sabun (CTPS) . Hal ini menunjukkan masih kurangnya praktek atau tindakan mencuci tangan di masyarakat (Anggraini, 2017).

Perolehan data yang didapatkan dari Center Disease Control (CDC) Amerika Serikat, terdapat 10.080 kematian dengan lebih dari $80 \%$ kematian diakibatkan karena diare. Di Asia selatan yaitu India terdapat 0,4 juta anak meningal dalam satu tahun yang disebabkan oleh diare. (Journal of Harvard School of Public Health, 2016). Diindonesia Menurut target cakupan pelayanan penderita diare yang datang ke sarana kesehatan dan kader kesehatan adalah $10 \%$ dari perkiraan jumlah penderita diare. Insidensi diare nasional hasil Survei Morbiditas Diare tahun 2016 yaitu sebesar 270/1.000 penduduk, maka diperkirakan jumlah penderita diare di fasilitas kesehatan pada tahun 2016 sebanyak 6.897 .463 orang, sedangkan jumlah penderita diare yang dilaporkan ditangani di fasilitas kesehatan adalah sebanyak 3.198 .411 orang atau 46,4\% dari target (Kemenkes, 2017).

Kesadaran masyarakat Indonesia untuk cuci tangan pakai sabun (CTPS) terbukti masih sangat rendah. hasil pelaksanaan program PHBS tentang mencuci tangan, menurut studi WHO tahun 2016 menyatakan, kejadian diare menurun $45 \%$ dengan perilaku mencuci tangan pakai sabun, 32\% dengan meningkatkan akses masyarakat terhadap sanitasi dasar, dan $39 \%$ perilaku pengelolaan air minum yang di rumah tangga, dengan upaya tersebut kejadian diare menurun sebesar $94 \%$ (Depkes RI, 2017).

Hasil penelitian menunjukkan bahwa pengetahuan dan perilaku cuci tangan dengan sabun berpengaruh terhadap kebersihan seseorang (Maria, 2017:3).

Seperti yang terjadi di Desa Rantau Durian umumnya masyarakat mayoritas petani. Masyarakat memiliki kebiasaan makan siang di sekitar ladang setelah bercocok tanam. Dengan kondisi tangan yang masih kotor mereka makan siang tanpa Cuci Tangan Pakai Sabun (CTPS) hal ini akan menimbulkan dampak baru bagi kesehatan yaitu dapat menyebabkan diare, penyakit perut dan keracunan pestisida.

Kegagalan untuk melakukan kebersihan dan kesehatan tangan yang tepat dianggap sebagian sebab utama infeksi nosokomial yang menular di pelayanan kesehatan, penyebaran mikroorganisme multiresisten dan telah diakui sebagai kontributor yang penting terhadap timbulnya wabah (Kusmiyati, 2015). Berdasarkan latar belakang diatas maka peneliti tertarik untuk melakukan penelitian yang berjudul "Hubungan Pengetahuan dan Sikap Terhadap Tindakan Cuci Tangan Pakai Sabun (CTPS).

\section{METODE PENELITIAN}

Penelitian ini merupakan jenis penelitian kuantitatif menggunakan survey analitik dengan pendekatan studi Cross Sectional untuk melihat hubungan sesaat antara variabel independen dan dependen.

Penelitian ini merupakan jenis penelitian kuantitatif menggunakan survey analitik dengan pendekatan studi Cross Sectional untuk melihat hubungan sesaat antara variabel independen dan dependen. Pengumpulan data sekaligus pada suatu saat artinya tiap subyek penelitian hanya di observasi sekali saja 
dan pengukuran dilakukan terhadap status karakter atau variabel subjek pada saat pemeriksaan (Notoatmodjo, 2011).

Penelitian ini dilakukan di wilayah Kabupaten Ogan Komering Ilir pada bulan Juni s.d Agustus 2020. Populasi pada penelitian ini adalah seluruh pasien dewasa yang datang berobat ke Puskesmas. Sampel pada penelitian ini adalah menggunakan tehnik pengambilan sampel menggunakan random sampling dan alat ukur yang digunakan adalah kuesioner berjumlah 67 orang.

Teknik untuk mengumpulkan data dengan menggunakan data primer diperoleh observasi dan wawancara secara langsung pada objek yang diteliti yaitu lansia. Data sekunder adalah data yang didapat dengan cara mempelajari buku- buku, bahan-bahan sumber bacaan dan tulisan yang ada hubungannya dengan masalah yang sedang dibahas.

Tehnik pengolahan data setelah data terkumpul secara manual kemudian di olah dengan menggunakan komputer melalui beberapa tahap antara lain; editing, coding, entri, dan cleaning. Analisis data menggunakan analisis univariat dan analisis bivariat.

\section{HASIL PENELITIAN \\ Analisa Univariat}

Analisis ini dilakukann untuk mengetahui distribusi frekuensi dan presentase dari variabel independen (Tindakan Mencuci tangan) dan variabel dependen (tingkat pengetahuan dan sikap).

Tabel 1

Distribusi frekuensi responden berdasarkan Karakteristik

\begin{tabular}{|c|c|c|c|c|}
\hline No & & Variabel & Frekuensi & $\%$ \\
\hline \multirow[t]{2}{*}{1} & Jenis Kelamin & Laki-laki & 38 & 56.7 \\
\hline & & Perempuan & 29 & 43.3 \\
\hline \multirow[t]{2}{*}{2} & Usia & Muda (17-39 Tahun) & 29 & 43.3 \\
\hline & & Dewasa Tua (> 39 Tahun) & 38 & 56.7 \\
\hline \multirow[t]{5}{*}{3} & Pendidikan & Tidak Tamat SD & 12 & 17.9 \\
\hline & & Tamat SD & 27 & 40.3 \\
\hline & & Tamat SLTP & 7 & 10.4 \\
\hline & & Tamat SMA & 18 & 26.9 \\
\hline & & Tamat PT & 3 & 4.5 \\
\hline \multirow[t]{2}{*}{4.} & Tindakan CPTS & Baik & 40 & 59.7 \\
\hline & & Buruk & 27 & 40.3 \\
\hline \multirow[t]{2}{*}{5.} & Tingkat & Baik & 34 & 50.7 \\
\hline & Pengetahuan & Kurang baik & 33 & 49.3 \\
\hline \multirow[t]{2}{*}{6.} & Sikap & Baik & 35 & 52.2 \\
\hline & & Buruk & 32 & 47.8 \\
\hline
\end{tabular}

Pada tabel di atas dapat dilihat bahwa sebagian besar responden dengan jenis kelamin laki-laki sebanyak 38 orang (56.7\%), responden yang usianya dewasa tua (> 39 tahun) sebanyak 38 orang $(56.7 \%)$, responden yang pendidikan hanya tamat SD sebanyak 27 orang (40.3\%), responden yang tindakan CPTSnya baik sebanyak 40 orang (59.7\%), responden yang tingkat pengetahuan baik sebanyak 34 orang $(50.7 \%)$, responden yang sikapnya baik sebanyak 35 orang $(52.2 \%)$.

\section{Analisa Bivariat}

Analisis ini dilakukan untuk mengetahui ada tidaknya hubungan antara 
variabel independen (tingkat pengetahuan) dan variabel dependen (tindakan CTPS). untuk melihat apakah ada hubungan antara variabel independen dengan dependen dapat digunakan uji statistik (chi-square) dengan program SPSS dengan menggunakan batas kemaknaan $\rho$ value $\alpha=$
0,05 , bila $\rho$ value $>0,05$ berarti tidak ada hubungan yang bermakna antara variabel independen dengan variabel dependen, dan sebaliknya bila $\rho$ value $\leq 0,05$ berarti ada hubungan yang bermakna antara variabel independen dengan variabel dependen.

\section{Hubungan Tingkat Pengetahuan dengan Tindakan CTPS}

Tabel 2

\begin{tabular}{|c|c|c|c|c|c|c|c|c|c|}
\hline \multirow{3}{*}{ No } & \multirow{3}{*}{$\begin{array}{l}\text { Tingkat } \\
\text { Pengetahuan }\end{array}$} & \multicolumn{4}{|c|}{ Tindakan CTPS } & \multicolumn{2}{|c|}{ Jumlah } & \multirow{3}{*}{ pvalue } & \multirow{3}{*}{ OR } \\
\hline & & \multicolumn{2}{|c|}{ Baik } & \multicolumn{2}{|c|}{ Buruk } & \multirow[t]{2}{*}{$\mathbf{N}$} & \multirow[t]{2}{*}{$\%$} & & \\
\hline & & $\mathbf{n}$ & $\%$ & $\mathbf{n}$ & $\%$ & & & & \\
\hline 1 & Baik & 27 & 79,4 & 7 & 20,6 & 34 & 100 & \multirow{3}{*}{$\begin{array}{c}0,002 \\
\text { (bermakna) }\end{array}$} & \multirow{3}{*}{5,934} \\
\hline \multirow[t]{2}{*}{2} & Kurang Baik & 13 & 39,4 & 20 & 60,6 & 33 & 100 & & \\
\hline & Total & 40 & & 27 & & 67 & & & \\
\hline
\end{tabular}

Dari tabel di atas, terlihat bahwa proporsi responden yang tingkat pengetahuannya baik sebanyak 27 orang (79.4\%), dibandingkan dengan frekuensi tingkat pengetahuan kurang baik sebanyak 13 orang $(39.4 \%)$.

Hasil uji Chi-Square diperoleh nilai $p$ value $0,002<0,05$, berarti ada hubungan yang bermakna antara tingkat pengetahuan dengan tindakan CPTS. Dari analisa didapat nilai OR 5.9 frekuensi tingkat pengetahuan yang baik dapat melakukan tindakan CPTS dengan baik dibandingkan dengan tingkat pengetahuannya kurang baik.

\section{Hubungan Sikap dengan Tindakan CPTS}

\section{Tabel 3}

Distribusi Responden Berdasarkan Sikap terhadap Tindakan Cuci Tangan Pakai Sabun (CTPS)

\begin{tabular}{|c|c|c|c|c|c|c|c|c|c|}
\hline \multirow[t]{3}{*}{ No } & \multirow{3}{*}{ Sikap } & \multicolumn{4}{|c|}{ Tindakan CTPS } & \multicolumn{2}{|c|}{ Jumlah } & \multirow{3}{*}{ pvalue } & \multirow{3}{*}{ OR } \\
\hline & & \multicolumn{2}{|c|}{ Baik } & \multicolumn{2}{|c|}{ Buruk } & \multirow[t]{2}{*}{$\mathbf{N}$} & \multirow[t]{2}{*}{$\%$} & & \\
\hline & & $\mathbf{n}$ & $\%$ & n & $\%$ & & & & \\
\hline 1 & Baik & 27 & 77,1 & 8 & 22,9 & 35 & 100 & 0,005 & 4023 \\
\hline 2 & buruk & 13 & 40,6 & 19 & 59,4 & 32 & 100 & & \\
\hline & Total & 40 & & 27 & & 67 & & & \\
\hline
\end{tabular}

Dari tabel di atas, terlihat bahwa proporsi responden yang tindakan CPTS nya denga sikap baik sebanyak 27 orang
(77.1\%). Lebih besar dibandingkan dengan responden yang sikapnya buruk sebanyak 13 orang $(40.6 \%)$. 
Hasil uji Chi-Square diperoleh nilai $p$-value $0,005<0,05$, berarti ada hubungan yang bermakna antara sikap dengan tindakan CPTS. Analisa didapat nilai OR 4.9 artinya bahwa responden yang sikapnya baik berpeluang 4 kali akan melakukan tindakan CPTS dengan baik dibandingkan dengan responden yang sikapnya buruk.

\section{PEMBAHASAN}

\section{Hubungan Tingkat Pengetahuan terhadap Tindakan CTPS}

Berdasarkan dari tabel diatas bahwa dari 67 responden didapatkan 27 responden yang tingkat pengetahuan baik terhadap tindakan CTPS baik lebih besar berjumlah $27(79,4 \%)$ responden dibandingkan dengan tingkat pengetahuan kurang baik terhadap tindakan CTPS baik berjumlah 13 $(39,4 \%)$ responden..

Dari hasil uji chi square didapat nilai $p$ value sebesar $0,002<\alpha=0,05$. Hal ini berarti ada hubungan yang bermakna antara tingkat pengetahuan dengan tindakan CTPS.Dengan demikian hipotesis yang menyatakan ada hubungan antara pendidikan terhadap tindakan mencuci tangan terbukti secara statistik.

Pengetahuan (knowledge) merupakan hasil dari tahu, dan ini terjadi setelah orang melakukan penghindaran terhadap suatu objek tertentu. Pengindaran terjadi melalui pancaindra manusia, yakni indra penglihatan, pendengaran, penciuman, rasa, dan raba. Sebagian besar pengetahuan manusia diperoleh melalui mata dan telinga.Pengetahuan atau kognitif merupakan domain yang sangat penting dalam membentuk tindakan seseorang (overt behavior). Karena dari pengalaman dan penelitian terbukti bahwa perilaku yang didasari oleh pengetahuan akan lebih bermakna luas dari pada perilaku yang tidak didasari oleh pengetahuan (Notoatmodjo, 2017).

Penelitian yang dilakukan Widya Utami (2015) bahwa ada hubungan antara pengetahuan dengan kebiasaan mencuci tangan, pengetahuan yang baik akan memberikan dampak yang baik bagi seseorang sehingga menjadi suatu kebiasaan untuk melakukan tindakan mencuci tangan.

Peneliti menyimpulkan bahwa seseorang yang mempunyai pengetahuan yang baik, maka akan mempunyai tindakan yang baik pula.

\section{Hubungan Sikap Terhadap Tindakan CTPS}

Berdasarkan dari tabel diatas dari 67 responden dapat dilihat bahwa dari sikap baik terhadap tindakan CTPS baik lebih besar berjumlah 27 (77,1) responden, dibandingkan dengan sikap buruk terhadap tindakan CTPS baik berjumlah 13 (40,6\%) responden.

Dari hasil uji chi squaredidapat nilai $p$ value sebesar $0,005<\alpha=0,05$. Hal ini berarti ada hubungan yang bermakna antara sikap terhadap tindakan CTPS terbukti secara statistik. Dengan demikian hipotesis yang menyatakan ada hubungan antara sikap terhadap minat tindakan CTPS terbukti secara statistik.

Penelitian yang dilakukan Audria (2014) bahwa sikap yang baik akan mempengaruhi seseorang melakukan tindakan yang baik.

Sikap adalah perasaan seseorang tentang obyek, aktivitas, peristiwa dan orang lain. Perasaan ini menjadi konsep yang merepresentasikan suka atau tidak sukanya (positif, negatif, atau netral) seseorang pada sesuatu. Sikap menjadi faktor predisposisi untuk melakukan atau tidak melakukan suatu perilaku tertentu, sikap menjadi proses kesadaran yang sifatnya individual. Hal ini berarti proses ini terjadi pada diri individu secara subjektif dan unik (Wawan, 2010).

Peneliti dapat menyimpulkan bahwa sikap berasal dari pengalaman, atau dari orang yang dekat dengan kita. Sikap yang baik otomatis akan mempunyai tindakan yang baik pula. 


\section{KESIMPULAN}

1. Ada Hubungan Tingkat Pengetahuan secara parsia terhadap Tindakan Cuci Pakai Tangan Sabun (CTPS). Nilai $P$ value 0,002 .

2. Ada Hubungan Tingkat Sikap secara parsial terhadap Tindakan Cuci Tangan Pakai Sabun (CTPS). Nilai p-value 0,009 .

\section{SARAN}

Bagi Puskesmas sebagai bahan evaluasi untuk mengembangkan kesehatan khususnya tentang pendidikan Cuci Tangan Pakai Sabun (CTPS).

\section{UCAPAN TERIMA KASIH}

Penulis mengucapkan banyak terima kasih kepada pihak Puskesmas yang telah membantu dan mendukung dalam terlaksananya penelitian ini.

\section{DAFTAR PUSTAKA}

Anggraini, (2017). Perilaku Organisasi. Jakarta: Cendekia.

Budiman, (2015).Raih kembali kesehatan. Jakarta: PT Kompas media nusantara.

Dahlan dan Umrah.(2013). Buku ajaran ketrampilan dasar praktik kebidanan. Malang: Intimedia.

Depkes RI. (2017). 10 pesan hidup sehat dalam kedaruratan. Depkes RI.

Kartono, K. (2015). Kamus psikologi. Bandung: CV. Pionir.

Kusmiyati, 2015. Keterampilan Dasar Praktek Klinik. Nuha Medika, Yogyakarta.

Nursalam.(2013). Pendekatan praktek metodologi riset keperawatan.Jakarta : CV. Sagung Seto
Notoatmodjo, S. (2017).Promosi kesehatan dan ilmu perilaku. Jakarta:Rineka Cipta.

Muchlisin, (2019).Ilmu kesehatan masyarakat teori dan aplikasi.Jakarta : Salemba Medika.

Supardi, (2017). Prosedur penelitian: Suatu pendekatan praktik. (Edisi.Revisi).Jakarta : Rineka Cipta.

Surwano, 2014. Pendidikan Anak Usia Dini.Sawon, Bantul, Yogyakarta.

Utami.(2014). Perilaku Hidup Bersih Dan Sehat. Jakarta: Trans Info Media.

Wijaya. (2015). Diare Pahami Penyakit dan Obatnya (1st ed.). Yogyakarta: Citra Aji Pratama.

Wawan, (2015). Ajaran Ketrampilan Dasar Praktik Keperawatan. Malang: Inti Media.

Adelia, (2016) Gambaran Tingkat Pengetahuan Dan Sikap Mencuci Tangan Pada Ibu Rumah Tangga Anggota Posyandu Di Wilayah Kerja Uptd Puskesmas Kecamatan Pontianak Utara. https://media.neliti.com/media/publi cations/192769-ID-gambarantingkat-pengetahuan-dan-sikapm.pdf. Diakses 26-Mei-2020

Audria, (2019). Hubungan Pengetahuan Dan Sikap Terhadap Perilaku Cuci Tangan Pada Masyarakat Kelurahan Pegirian Tahun 2019. http://journal.stikeskendal.ac.id/inde x.php/PSKM/article/view/635. Diakses 1.5.2020

Annisah, (2018).Hubungan Faktor-faktor yang mempengaruhi perilaku mencuci Tangan di Masyarakat 
Tahun

2018.file:///C:/Users/Esti/Downloads 1514-Article\%20Text-1045-1-1020170829\%20(1).pdf. Diakses 1.5.2020

Aryani Kusumawardhani, (2016). Pengetahuan, Sikap, Dan Tindakan Mencuci Tangan Yang Benar Pada Siswa Kelas 1 Dan 2 Di Sdn 2 Karanglo, Klaten Selatan. file:///C:/Users/Ernawati/Downloads/ 23-Article\%20Text-39-1-1020190525.pdf. Diakses 27-Mei-2020

Kementerian Kesehatan. (2017). 7 Masalah Kesehatan Akibat Malas Cuci Tangan.Retrieved March 19, 2019, from

http://promkes.kemkes.go.id/?p=820 3. Diakses 30.4.2020

Retno.(2016). Perilaku hidup bersih untuk mencegah diare.From http://www.depkes/promosi kesehatan.go.id. Diakses 25.4.2020

Saputra, (2013).Faktor Determinan Perilaku Cuci Tangan Pakai Sabun (CTPS) Pada Masyarakat di Tanah Kalikediding.Promkes, 4.https://ejournal.unair.ac.id/PROM
KES/article/view/5807/3716.

Diakses 29.4.2020

Susianti, (2018).Perilaku Cuci Tangan Pakai Sabun Studi Kualitatif pada IbuIbu di Kampung Nelayan Muara Angke Jakarta Utara; Studi Kualitatif.Arsip Kesehatan Masyarakat, 2 (Vol 2 No 1 (2017)).Dari https://doi.org/https://doi.org/10.222 36/arkesmas.v2i1.514 .diakses. Diakses 29.4.2020

Widya Utami. (2015). Faktor-Faktor Yang Berhubungan Dengan Kebiasaan Cuci Tangan Pakai Sabun Pada Masyarakat Di Desa Cikoneng Kecamatan Ganeas Kabupaten Sumedang Tahun 2015. Diakses dari http://repository.unej.ac.id/handle/12 3456789/57330. Diakses 25.4.2020 